ARTICLE

Received 14 Mar 2015 | Accepted 21 Jul 2015 | Published 15 Sep 2015

DOI: $10.1038 /$ ncomms 9123

\title{
A predictive structural model for bulk metallic glasses
}

\author{
K.J. Laws ${ }^{1}$, D.B. Miracle ${ }^{2} \&$ M. Ferry ${ }^{1}$
}

Great progress has been made in understanding the atomic structure of metallic glasses, but there is still no clear connection between atomic structure and glass-forming ability. Here we give new insights into perhaps the most important question in the field of amorphous metals: how can glass-forming ability be predicted from atomic structure? We give a new approach to modelling metallic glass atomic structures by solving three long-standing problems: we discover a new family of structural defects that discourage glass formation; we impose efficient local packing around all atoms simultaneously; and we enforce structural self-consistency. Fewer than a dozen binary structures satisfy these constraints, but extra degrees of freedom in structures with three or more different atom sizes significantly expand the number of relatively stable, 'bulk' metallic glasses. The present work gives a new approach towards achieving the long-sought goal of a predictive capability for bulk metallic glasses.

\footnotetext{
${ }^{1}$ School of Materials Science and Engineering, UNSW Australia, Sydney, New South Wales 2052, Australia. ${ }^{2}$ Air Force Research Laboratory, Materials and Manufacturing Directorate, 2230 Tenth Street, Wright-Patterson AFB, Ohio 45433 USA. Correspondence and requests for materials should be addressed to D.B.M. (email: daniel.miracle@us.af.mil).
} 
F rom the moment metallic glasses were discovered in 1960 (ref. 1), questions arose about their atomic structure. The dense random packing (DRP) model was introduced independently to describe the structure of monatomic liquids $^{2-4}$. The metallic glass community adopted the DRP model, even though it consisted of single-sized atoms and metallic glasses always had atoms of different sizes. Attempts to put smaller atoms in the natural gaps of the DRP model ${ }^{5,6}$ were abandoned since the gaps were too small and too few to agree with metallic glasses ${ }^{7}$. In a dramatic break from the DRP model, the stereo-chemically defined (SCD) model used efficiently packed, solute-centred clusters with total coordination of 9 as structural building blocks for metalmetalloid glasses ${ }^{8}$. This model included atoms of unequal size and gave a physical basis for chemical short-range order (SRO) known to exist in metallic glasses. However, it could not explain the medium-range order (MRO) found soon after the SCD model was introduced ${ }^{9}$, there was never a satisfying description of how efficiently packed clusters were arranged to avoid packing frustration ${ }^{10}$, and it could not explain the full range of atom sizes and concentrations that produced metallic glasses. Studies clearly showed that metallic glass structures were, indeed, efficiently packed ${ }^{11-14}$, but none were able to explain how glass structures accomplished this feat. Reviews of the first 30 years of metallic glass structural modelling are available ${ }^{15-17}$.

Thus, 40 years after their discovery ${ }^{1}$, three seminal questions for metallic glasses remained: what is their atomic structure; how does structure influence glass-forming ability (GFA); and what chemical interactions are needed for good GFA? Great strides have been made in the past 10 years in resolving the first question. By extending ideas from the SCD model, a new model that uses efficiently packed solute-centred atom clusters as structural building blocks has been established ${ }^{18,19}$, and quantitative predictions of $\mathrm{SRO}^{20}, \mathrm{MRO}^{21}$ and density ${ }^{22}$ have validated and refined this efficient cluster-packing (ECP) model. This model gives new ways to interrogate atomic simulations ${ }^{19}$, opens new ways to analyse experimental data ${ }^{23}$ and has inspired new experimental techniques ${ }^{24}$. Bulk metallic glasses (BMGs, glasses with the smallest amorphous dimension $\geq 1 \mathrm{~mm}$ ) were first discovered nearly 25 years ago ${ }^{25,26}$, but finding new BMGs still requires tedious trial-and-error methods. However, the ECP model has inspired the discovery of new BMGs without full recourse to empiricism ${ }^{27-30}$. Efficient local atomic packing around the minority (solute) atoms and a preference for bonds between unlike atoms gives the physical motivation for structure-forming clusters ${ }^{16}$. Efficient packing is achieved for specific radius ratios between solute and solvent atoms, $R_{Z}^{*}$, that give solute-lean clusters with a central solute atom surrounded by $Z$ solvent atoms ${ }^{31}$. The most stable glasses are typically solute rich, where the solute atom first shell contains both solute and solvent atoms. The ECP model gives a good account of both solute-lean and solute-rich structures ${ }^{32}$. Additional details of this model are given in ref. 21 .

In spite of this progress, current structural models are not predictive. The ECP model describes the structure once a glass is formed, but it cannot predict which structures will have good GFA (defined here as the maximum fully amorphous thickness or diameter produced by quenching from the liquid), which will form marginal glasses, and which will not produce glasses at all. Important questions that may give insights into GFA remain unanswered. Of the dozen $R_{Z}^{*}$ values that give efficient local atomic packing $(9 \leq Z \leq 20)$, there is no explanation why five values are strongly preferred, giving all of the most stable binary glasses $^{32}$. Even more troubling, the basis for preferred radius ratios that underpins the ECP model seems to disappear in solute-rich glasses, where efficient filling of the first coordination shell can be achieved at any radius ratio by adjusting the constitution of the first shell. The structural features that are essential for metallic glasses to compete with crystalline phases thus remain a mystery.

Here we solve three persistent problems to give new insights into this seminal question: we identify a new family of structural defects that discourage metallic glass formation; we learn how to enforce efficient packing around every atom in the glass simultaneously; and we determine the relative atom sizes and concentrations and the distinct clusters that they enable for self-consistent compositions. These ideas are consistent with earlier work on the ECP model, and solution of these problems emphasizes atomic structures that are 'solute-rich' (have sufficiently high concentrations so that cluster first shells must contain all of the atom species present) or where the smaller atoms are the majority species. Such structures represent a large number of BMGs, and their inclusion was not always clear in earlier developments of the ECP model. The present work thus gives a more predictive, robust and complete description of metallic glass atomic structures.

\section{Results}

Glass suppression via super-substitutional atomic defects. To predict which alloys will form glasses, we must first understand why some alloys do not. We consider binary systems of A and $\mathrm{B}$ atoms with radii $r_{\mathrm{A}}<r_{\mathrm{B}}$ and $\mathrm{A}$ atom fraction $f_{\mathrm{A}}$. Atom size-concentration space is bounded by $0 \leq f_{\mathrm{A}} \leq 1$ and radius ratios $0 \leq R_{\mathrm{A} / \mathrm{B}} \leq 1$, where $R_{\mathrm{A} / \mathrm{B}}=r_{\mathrm{A}} / r_{\mathrm{B}}$. Metallic glasses are generally limited to $0.6 \leq R_{\mathrm{A} / \mathrm{B}} \leq 1$ due to the radii of metallic elements ${ }^{32}$. Glasses with $f_{\mathrm{A}}>0.6$ account for $40 \%$ of atom size-composition space but fewer than $20 \%$ of binary metallic glasses, so that some unknown feature seems to discourage binary glasses when the small atom is the majority species (Fig. 1a).

Binary glasses are forbidden below a minimum solute fraction, $f_{\mathrm{A}, \min }=1 /(Z+1)$, where each solute is surrounded only by solvent atoms and each solvent touches only one solute. Glasses can form above $f_{\mathrm{A}, \text { min }}$, but they are discouraged between $f_{\mathrm{A}}$, min and the higher solute fraction, $f_{\text {crit }}$, that is needed for glasses to compete more effectively with crystals. Solute atoms produce local elastic strains in crystal structures that compete with the glass, and a glass can form when the volume strain throughout the competing crystal reaches a critical value, $\varepsilon_{\text {crit }}$ (refs 33,34 ). Solutes with large local strains can be far apart (have low $f_{\text {crit }}$ ), while solutes with smaller strains must have higher concentrations to reach $\varepsilon_{\text {crit }}$. The magnitude of elastic strains depends on the type of defects. Substitutional defects dominate when $R_{\mathrm{A} / \mathrm{B}}>0.81$ and $\mathrm{A}$ atoms are solutes (left-hand side of Fig. 1a) ${ }^{33,34}$ and interstitial defects occur when $R_{\mathrm{A} / \mathrm{B}}<0.81$ (ref. 34). The critical concentration to destabilize competing crystals, $f_{\text {crit }}$, decreases as $R_{\mathrm{A} / \mathrm{B}}$ decreases, reaches a minimum near $R_{\mathrm{A} / \mathrm{B}}=0.81$, then increases with further reduction in $R_{\mathrm{A} / \mathrm{B}}$ (Fig. 1a). For B-atom solutes (right-hand side of Fig. 1a), earlier approaches only considered substitutional defects where a solute replaced a single solvent atom ${ }^{33,34}$. This gives $f_{\text {crit }}$ values that decrease continuously as $R_{\mathrm{A} / \mathrm{B}}$ decreases $\left(f_{\text {crit }}=1-f_{\mathrm{A}}\right.$ when $\mathrm{B}$ is the solute), and a large portion of the sparsely populated size-composition space for $f_{\mathrm{A}}>0.6$ remained unexplained.

Here we show that large solutes may replace more than one solvent atom. These super-substitutional defects (see Methods) have lower strains-and higher $f_{\text {crit }}$ values-than single substitutional defects near the radius ratios where these defects form. Five super-substitutional $f_{\text {crit }}$ peaks now discourage most size-composition combinations on the right-hand side of Fig. 1a. This new family of atomic defects explains for the first time why 

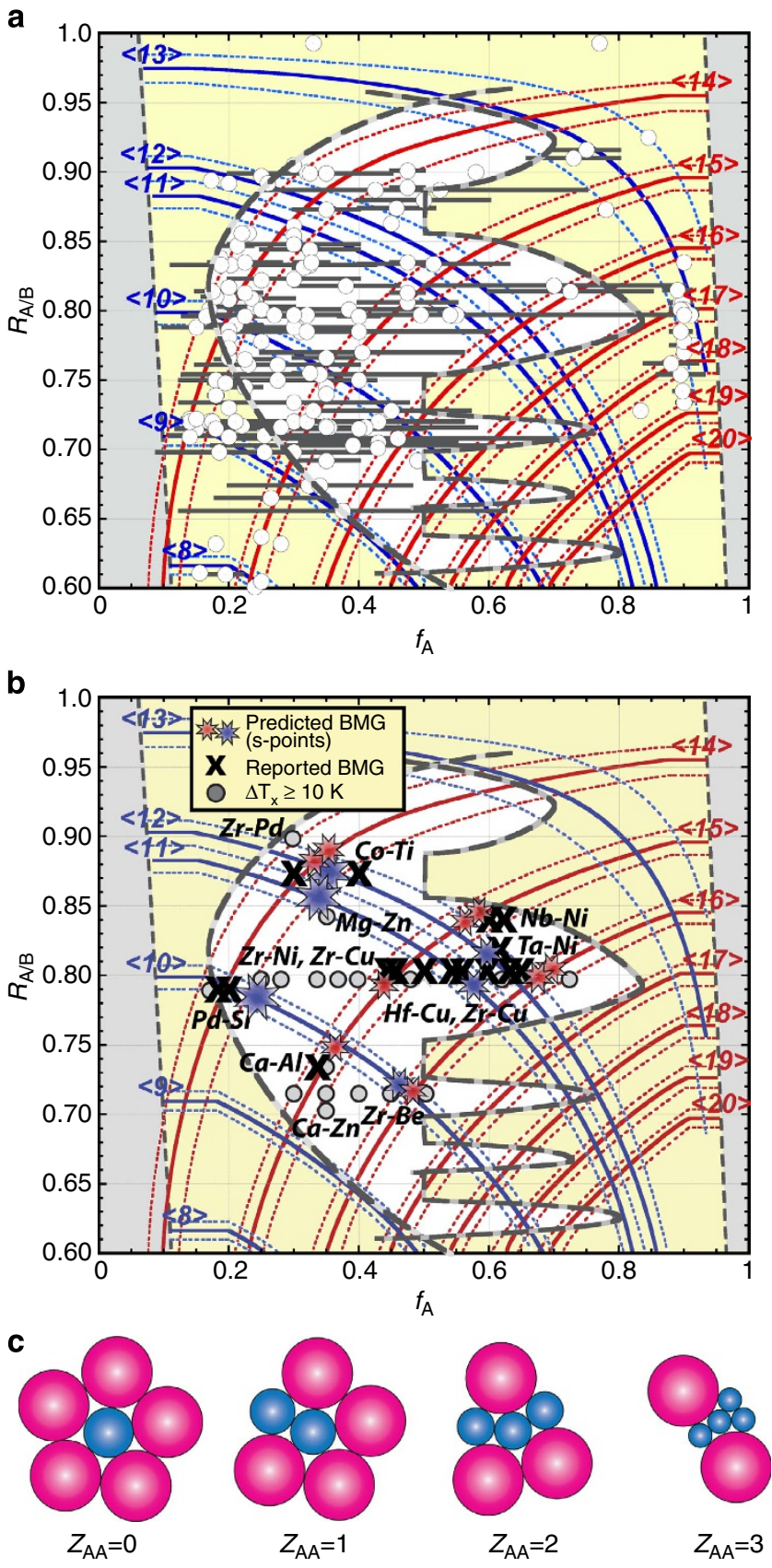

Figure 1 | Efficient cluster-packing curves. Efficiently packed $(P=100 \pm 1 \%) A$ - and $B$-centred clusters of fixed total coordination numbers $\left\langle Z_{\mathrm{A} \text {,tot }}\right\rangle$ (blue lines) and $\left\langle Z_{\mathrm{B} \text {,tot }}\right\rangle$ (red lines) as a function of $R_{\mathrm{A} / \mathrm{B}}$ (nominal radius ratio) and $f_{\mathrm{A}}$ (A atom fraction). These curves are superimposed with (a) all binary metallic glasses (empty circles). Horizontal bars show the composition range for each system. Regions excluded by a minimum solute criterion are shown by grey regions and relative atom sizes and concentrations discouraged by competing crystalline defects are shown by yellow areas. (b) Binary BMGs (black crosses) and glasses with $\Delta T_{x}>10 \mathrm{~K}$ (grey circles) occur near $\mathrm{S}$-points (eight-point stars), where packing is efficient around both clusters simultaneously. (c) $R_{\mathrm{A} / \mathrm{B}}$ decreases with increasing $Z_{\mathrm{AA}}$ and $f_{\mathrm{A}}$ in clusters of fixed $\left\langle Z_{A, \text { tot }}\right\rangle$, since the size difference between $A$ and $B$ atoms has to increase to maintain efficient packing as smaller $A$ atoms replace larger $B$ atoms in the 1st shell. In B-centred clusters, the size difference between $A$ and $\mathrm{B}$ atoms has to decrease $\left(R_{\mathrm{A} / \mathrm{B}}\right.$ increases) with increasing $f_{\mathrm{A}}$. Data are taken from refs 32,51 . The atom radii used in the present work are given in Supplementary Table 1. the large portion of atom size-composition space at $f_{\mathrm{A}}>0.6$ produces relatively few metallic glasses.

Simultaneous efficient packing in binary metallic glasses. We now turn our attention from excluded and discouraged glasses to predicting those that are most likely to form metallic glasses. Packing efficiency has long been considered important ${ }^{12,14,35}$ and local packing efficiency around solute atoms is the basis for the ECP model. The concept that packing may be efficient around both solute and solvent atoms ${ }^{36}$ was not included in the ECP model earlier due to several problems. The packing efficiency bounds ( $\pm 10 \%$ ) were too broad to be meaningful, validation was given for only a small number of marginal glasses, and the earlier work did not give a physical model proving that efficient packing could be achieved around all atoms simultaneously. Broad statements have suggested that local packing is efficient around solute and solvent atoms ${ }^{37}$, but this remains an unproven concept that still requires a compelling physical model.

Here we develop a new approach to enforce efficient local packing around all atom species that overcome these concerns. We start by plotting efficiently packed cluster curves for each total coordination number (Fig. 1). These curves hold constant the packing efficiency $\left(P^{\mathrm{i}}\right)$ and the total number of atoms in the first shell of $i$-centred clusters $\left(Z_{i, \text { tot }}\right)$. Composition is changed by adjusting the partial coordination numbers, $Z_{\mathrm{ij}}$, given as the number of $j$ atoms in the first shell of $i$-centred clusters. The atom fractions of structures derived from these clusters are

$$
f_{j}^{i}=\frac{Z_{i j}+\lambda}{Z_{i, \text { tot }}+\lambda} \text { when } i=j \quad f_{j}^{i}=\frac{Z_{i j}}{Z_{i, \text { tot }}+\lambda} \text { when } i \neq j
$$

where $j$ is the atom for which the composition is given. $\lambda$ is the number of solute atoms on solute sites per cluster $(1 \leq \lambda \leq 4$, and the value of $\lambda$ has only a minor effect in the present work). We adjust $R_{\mathrm{A} / \mathrm{B}}$ for each $Z_{\mathrm{ij}}$ to keep clusters efficiently packed (Fig. 1 inset). The radius ratios in these efficiently packed $A$ - and B-centred clusters are (see Methods)

$$
R_{\mathrm{A} / \mathrm{B}}^{\mathrm{A}}=\frac{Z_{\mathrm{AB}}}{X^{\mathrm{A}}-Z_{\mathrm{AA}}} \quad R_{\mathrm{A} / \mathrm{B}}^{\mathrm{B}}=\frac{X^{\mathrm{B}}-Z_{\mathrm{BB}}}{Z_{\mathrm{BA}}}
$$

where $X^{i}=\left(P^{i}\right)\left(Z_{i, \text { tot }}\right) / R_{Z}^{*, i}$ and $R_{Z}^{*, i}$ is the radius ratio that gives ideal packing for an integer number $Z$ of identical atoms in the first shell of $i$-centred clusters ${ }^{31}$.

All binary BMGs essentially fall within $P=100 \pm 1 \%$ of at least one cluster (Fig. 1b), as do glasses discouraged by substitutional, interstitial and super-substitutional defects (Fig. 1a). Where two curves intersect, $f_{\mathrm{A}}, R_{\mathrm{A} / \mathrm{B}}$ and $P$ are the same in A-centred and B-centred clusters simultaneously. This is a remarkable convergence, and some of the most stable binary BMGs $\left(\mathrm{Pd}_{100-x} \mathrm{Si}_{x}, \quad 18 \leq x \leq 20, \mathrm{Cu}_{64} \mathrm{Zr}_{36}\right.$ and $\left.\mathrm{Cu}_{65} \mathrm{Hf}_{35}\right)$ are nearly coincident with two such intersections. However, there is no compelling correlation between these intersections and the full set of binary BMGs (Fig. 1b). Below we show that such a convergence can be achieved in some (but not all) binary systems, but at different atom sizes and compositions than those indicated by curve intersections.

Structural self-consistency in binary metallic glasses. Two conditions must be satisfied rigorously in physical systems. First, the nominal radius ratios of $i$-centred clusters, $R_{\mathrm{A} / \mathrm{B}}^{i}$, must be identical in both A- and B-centred clusters

$$
R_{\mathrm{A} / \mathrm{B}}^{\mathrm{A}}=R_{\mathrm{A} / \mathrm{B}}^{\mathrm{B}}
$$

Structural self-consistency is the second requirement. Self-consistency recognizes that the number of $\mathrm{A}-\mathrm{B}$ bonds in a structure is fixed, so that the number of $\mathrm{A}-\mathrm{B}$ bonds 'originating' from 


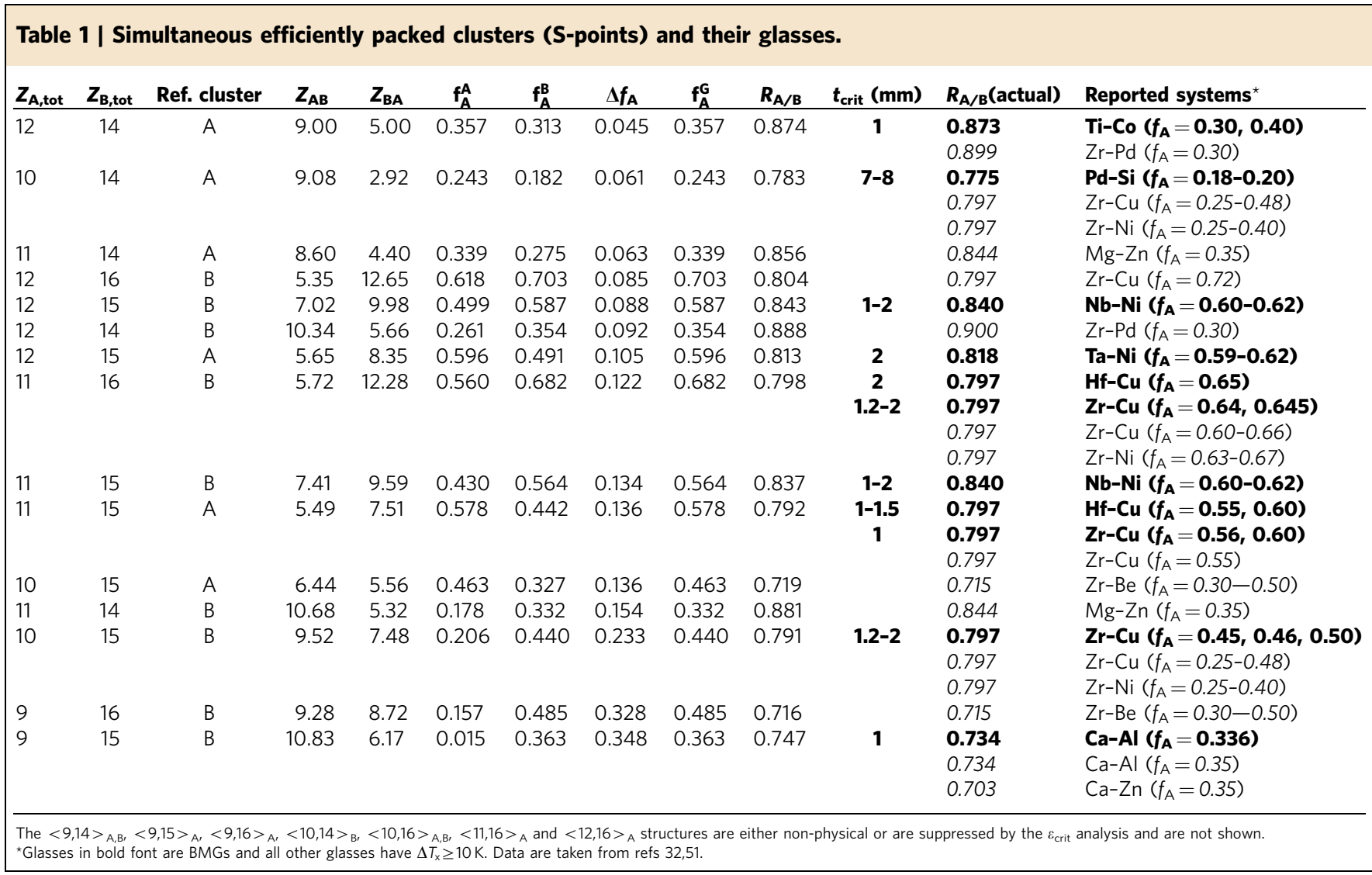

$\mathrm{A}$ atoms equals the number of $\mathrm{A}-\mathrm{B}$ bonds 'originating' from $\mathrm{B}$ atoms. This gives the self-consistency equation

$$
f_{\mathrm{A}}^{\mathrm{G}} Z_{\mathrm{AB}}=f_{\mathrm{B}}^{\mathrm{G}} Z_{\mathrm{BA}}
$$

where $f_{i}^{\mathrm{G}}$ is the global atom fraction of element $i$. equation (4) is used in diffraction analyses ${ }^{38}$, but has not been used previously in structural modelling. To determine the structures that allow efficient packing around both atoms in the same structure, we solve equations (3 and 4) simultaneously (see Methods). The results are given in Table 1 and Fig. 1b. More detailed discussion of excluded, discouraged and preferred atom sizes and concentrations is given in Supplementary Notes 1-3 and Supplementary Figs 1-3.

S-points and the most stable binary metallic glasses. Discrete atom sizes and concentrations that simultaneously satisfy equations (3 and 4) are called S-points. These are the only points in binary size-composition space where packing is efficient around both atoms simultaneously. Each $<Z_{\mathrm{A} \text {,tot }}, Z_{\mathrm{B} \text {,tot }}>$ curve intersection has two solutions. A-reference S-points (blue stars in Fig. 1b) set the $\mathrm{A}$ atom fraction in the glass, $f_{\mathrm{A}}^{\mathrm{G}}$, to the composition of A-centred clusters, $f_{\mathrm{A}}^{\mathrm{A}}$. B-reference S-points (red stars in Fig. 1b) give solutions where $f_{\mathrm{A}}^{\mathrm{G}}=f_{\mathrm{A}}^{\mathrm{B}}$. Some S-points are near the corresponding $<Z_{\mathrm{A} \text {,tot }}, Z_{\mathrm{B} \text {,tot }}>$ intersection, but some are not. Some $S$-points are close together and some $S$-points are suppressed by the $\varepsilon_{\text {crit }}$ criterion, so that only about a dozen distinct S-points exist. A graphical description of how S-points are determined is given in Supplementary Note 3 and Supplementary Fig. 3.

$\mathrm{Pd}-\mathrm{Si}$ glasses are by far the most stable binary BMGs, suggesting that some S-points have better GFA than others. The local compositions of A- and B-centred clusters, $f_{\mathrm{A}}^{\mathrm{A}}$ and $f_{\mathrm{A}}^{\mathrm{B}}$, are not the same in binary glasses (see Table 1). This is because self-consistency requires partial coordination numbers that give different compositions in A- and B-centred clusters. However, how can A- and B-centred clusters have different local compositions in the same glass? The cluster compositions in equation (1) are only preferences. For example, equation (1) implies that all $i$-centred clusters are identical. While particular clusters dominate a given glass, a range of quasi-equivalent clusters can occur ${ }^{19}$. Further, the number of occupied $\beta$ and $\gamma$ sites (structural sites between an octahedron and a tetrahedron of clusters, respectively ${ }^{21}$ ) in a structure may vary. Finally, the ECP model assumes that $\beta$ and $\gamma$ sites are vacant or are occupied by solute atoms ${ }^{21}$, but solvent atoms may also occupy these sites. The curves in Fig. 1 thus show preferences and do not give exact glass compositions.

The composition difference between A- and B-centred clusters gives a chemical frustration that needs to be minimized. We propose that S-points with the best GFA will have the smallest composition difference,

$$
\Delta f_{\mathrm{A}}=\left|f_{\mathrm{A}}^{\mathrm{A}}-f_{\mathrm{A}}^{\mathrm{B}}\right|
$$

$\Delta f_{\mathrm{A}}$ is the degree to which a structure must adjust from preferences in equation (1) to achieve efficient packing around both species and to satisfy self-consistency. Compositions cannot adjust by changing $Z_{\mathrm{AB}}$ or $Z_{\mathrm{BA}}$, which are fixed by equations ( 3 and 4 ), but can change by altering the number of $\lambda$ sites occupied or by changing the types of atoms on $\lambda$ sites. A change of one atom per cluster gives a composition change of $\pm 1 /\left(Z_{i, \text { tot }}+1\right)$ as a benchmark against which $\Delta f_{\mathrm{A}}$ can be compared. The three best $\mathrm{S}$-points have $\Delta f_{\mathrm{A}}$ below this benchmark and are shown by larger stars in Fig. 1b. Table 1 sorts S-points by increasing $\Delta f_{\mathrm{A}}$. Pd-Si glasses have the best GFA of any binary $\mathrm{BMG}$ and have the second smallest $\Delta f_{\mathrm{A}}$. Few glasses 
have been made near the remaining two preferred S-points (compare Fig. 1a,b), suggesting a good place for future exploration.

There has never been an explanation for why the most common $R_{\mathrm{A} / \mathrm{B}}$ in binary glasses is near 0.80 and why BMGs form over a nearly continuous composition range of $0.45 \leq f_{\mathrm{A}} \leq 0.65$ at this radius ratio ${ }^{32}$. Four S-points $\left.(<10,15\rangle_{\mathrm{B}}, \quad<11,15\right\rangle_{\mathrm{A}},\langle 11,16\rangle_{\mathrm{B}}$ and 12,16$\rangle_{\mathrm{B}}$, where the subscript indicates the reference structure) fall within an exceptionally narrow range of $R_{\mathrm{A} / \mathrm{B}}=0.798 \pm 0.007$ and span compositions from $0.44 \leq f_{\mathrm{A}} \leq 0.70$. Over half the known binary BMGs fall between these S-points. This shows that glasses can form between $S$-points that have the same $R_{\mathrm{A} / \mathrm{B}}$ values and are compositionally close to each other. The GFA of such glasses may depend on the compositional distance from the bounding S-points. Thus, relatively stable glasses form between $<10,14\rangle_{\mathrm{A}}$ and $\langle 10,15\rangle_{\mathrm{B}} \mathrm{S}$-points in the range $0.25 \leq f_{\mathrm{A}} \leq 0.40$ (Fig. 1), but they do not form BMGs because the composition distance between the bounding $\mathrm{S}$-points is large. The radius ratio of $\mathrm{Cu}-\mathrm{Zr}$ and $\mathrm{Cu}-\mathrm{Hf}$ glasses $\left(R_{\mathrm{A} / \mathrm{B}}=0.797\right)$ is very close to the radius ratio of these $S$-points, and the widest composition range allowed by the $\varepsilon_{\text {crit }}$ criteria also occurs near $R_{\mathrm{A} / \mathrm{B}}=0.80$. Together, these features explain for the first time why alloys with $R_{\mathrm{A} / \mathrm{B}} \cong 0.80$ are by far the most common and the most stable binary glasses.

It seems fortuitous that the favoured radius ratio $R_{\mathrm{A} / \mathrm{B}} \cong 0.80$ is so close to the ideal radius ratio $R_{10}^{*}=0.799$ for efficient packing of $\langle 10\rangle$ clusters with only $B$ atoms in the first shell. The present work shows that solute-rich clusters with $Z_{i \text {,tot }}=11$, $12,14,15$ and 16 are also produced at this radius ratio (Fig. 1), consistent with experimental $Z_{i j}$ data $^{20}$.

Agreement between predicted and observed binary glasses is good. No glasses occur in excluded regions. Glasses discouraged by atomic defects in competing crystals (yellow regions of Fig. 1) are relatively few, generally have one efficiently packed cluster (Fig. 1a) and are always marginal glasses (amorphous thickness, $t_{\mathrm{a}}<1 \mathrm{~mm}$ with a difference between crystallization and glass transition temperatures, $\left.\Delta T_{\mathrm{x}} \cong 0 \mathrm{~K}\right)$. S-points are uncommon, consistent with the restricted number of BMGs and near-BMGs $\left(t_{\mathrm{a}}<1 \mathrm{~mm}\right.$ but $\left.\Delta T_{\mathrm{x}} \geq 10 \mathrm{~K}\right)$. Each S-point has BMGs or nearBMGs (or both) nearby and all BMGs and near-BMGs are close to S-points. A most favoured S-point $\left.(<10,14\rangle_{\mathrm{A}}\right)$ gives the only exceptional binary BMG ( $\mathrm{Pd}-\mathrm{Si}$ glasses with $\left.t_{\mathrm{a}}>5 \mathrm{~mm}\right)$. The present model thus not only predicts whether or not a glass will form, but indicates whether the glass will be marginal, near-BMG, BMG or an exceptional BMG. The results in Table 1 for $P^{\mathrm{A}}=P^{\mathrm{B}}=100 \%$ are not substantially changed by varying $P^{\mathrm{A}}$ and $P^{\mathrm{B}}$ within $\pm 1 \%$, but agreement degrades outside these bounds. Thus, essentially all of the most stable binary metallic glasses discovered in over 50 years of extensive experimentation are well-represented by the present predictions.

Simultaneous efficient packing and ternary BMGs. The present approach shows a good ability to predict binary GFA, but the number of binary BMGs is small. There are many ternary BMGs, and so we extend these concepts to ternary glasses to better explore their robustness. We use systems of $\mathrm{A}, \mathrm{B}$ and $\mathrm{C}$ atoms with radii $r_{\mathrm{A}}<r_{\mathrm{B}}<r_{\mathrm{C}}$ and radius ratios $R_{\mathrm{A} / \mathrm{C}}=r_{\mathrm{A}} / r_{\mathrm{C}}, R_{\mathrm{B} / \mathrm{C}}=r_{\mathrm{B}} / r_{\mathrm{C}}$ and $R_{\mathrm{C} / \mathrm{C}}=1$. Some glasses with four or more chemically distinct species have only three significantly different atom sizes. For example, $\mathrm{Zr}-\mathrm{Al}-[\mathrm{Cu}, \mathrm{Ni}]$ and $\mathrm{Pd}-[\mathrm{Ni}, \mathrm{Cu}]-\mathrm{P}$ are generally considered as quaternary glasses, but since $r_{\mathrm{Ni}} \cong r_{\mathrm{Cu}}$ these glasses have only three significantly different atom sizes. Such glasses are considered as structural ternary glasses, since equal-sized atoms will occupy similar structural sites. For convenience, we show atoms of nearly equal size in brackets. In the same way, glasses with only four significantly different atom sizes are considered structural quaternary glasses, regardless of the number of chemical species. The relative atom sizes and concentrations of many ternary BMGs are plotted in Fig. 2.

Predicted relative atom sizes and concentrations for ternary BMGs are found using the same approaches for binary glasses. Excluded and discouraged structures fill ternary corners using $f_{\text {crit }}$ values from Fig. 1. For simplicity, a straight line connects pairs of $f_{\text {crit }}$ values on the ternary edges. Simultaneous efficient packing in ternary systems occurs along straight lines (see Methods). The bands in Fig. 2 show packing efficiencies of $100 \pm 2 \%$ for each $<Z_{\mathrm{A} \text {,tot}}, Z_{\mathrm{B}, \text { tot }}, Z_{\mathrm{C} \text {,tot }}>$ structure. Self-consistency significantly limits the number of binary atom sizes and concentrations with efficient packing around all species, but self-consistency is always achieved when the cluster composition is the same as the glass composition in ternary glasses due to extra degrees of freedom (see Methods). Thus, discrete S-points are not needed in more complex glasses and all of the ternary glass structures shown in Fig. 2 satisfy self-consistency. Details of the ternary systems in Fig. 2 are given in Supplementary Note 4 and Supplementary Table 3.

The present model is validated by comparing predicted atom sizes and concentrations with more than 230 reported ternary BMGs in 57 chemically distinct systems. Essentially all of these BMGs have atom sizes and concentrations where packing is simultaneously efficient around all atoms (all three bands overlap in Fig. 2). Over 40 of these ternary BMGs and 20 quaternary $\mathrm{BMGs}^{27-30}$ were first predicted using some of the present ideas, indicating their predictive capabilities. To further establish their predictive abilities, we used the present ideas to find 35 new Mg-based BMGs (Supplementary Table 4). These new discoveries include ternary systems never reported before: $\mathrm{Mg}-\mathrm{Ag}-\mathrm{Yb}$; $\mathrm{Mg}-\mathrm{Pd}-\mathrm{Ca}$ and $\mathrm{Mg}-\mathrm{Pd}-\mathrm{Yb}$. We also find the highest glass transition temperature for any $\mathrm{Mg}$-based $\mathrm{BMG}$ (485 $\mathrm{K}$ for $\left.\mathrm{Mg}_{67.5} \mathrm{Pd}_{25} \mathrm{Ca}_{7.5}\right)$. To put this achievement in perspective, thousands of compositions are usually needed using conventional trial-and-error methods to discover one new BMG. Combinatorial methods accelerate this process, but the failure-to-success ratio is still over 1,000 to 1 (ref. 39). The present model dramatically improves these odds-we produced 35 new BMGs from 44 predicted alloys.

These ideas suggest that the best BMGs will have atom sizes and concentrations that fall nearest the ideal packing lines in Fig. 2. The largest known glass diameter is $80 \mathrm{~mm}$ for fluxed $\mathrm{Pd}_{42.5}\left[\mathrm{Cu}_{30} \mathrm{Ni}_{7.5}\right] \mathrm{P}_{20}$ (ref. 40), an alloy that lies perfectly on ideal packing lines for $\langle 10,13,15\rangle$ structures. Since identical structures can occur in different chemical systems, Fig. 2 mixes contributions to glass stability from structure (efficient packing) and chemical effects. To isolate the structural contribution, we consider ternary BMGs with different concentrations of the same elements. The glasses must fall in a relatively narrow composition band to avoid transitioning to a different structure. We plot glass thickness against the mean packing efficiency around the $n$ constituent atoms, $\bar{P}=\frac{1}{n} \sum_{i}^{n} P_{i}$ (Fig. 3). $\mathrm{Pd}-\mathrm{Ni}-\mathrm{P}$ and $\mathrm{Ca}-\mathrm{Mg}-\mathrm{Zn}$ ternary glasses both show the maximum amorphous thickness when the mean packing efficiency is closest to $100 \%$. The amorphous thickness drops significantly as atoms become over-packed $(\bar{P}<100 \%)$ or underpacked $(\bar{P}>100 \%)$. This figure shows a sharp 'cusp' behaviour similar to the effect of composition on GFA documented for many other systems ${ }^{41}$.

Preferred atom sizes and concentrations in Fig. 2 with no reported BMGs may be regions for future exploration. However, some efficiently packed structures may lack combinations of 'realworld' atoms to give the radius ratios and chemical interactions needed to form BMGs. Thus, BMGs might not be produced in every preferred region. 
a

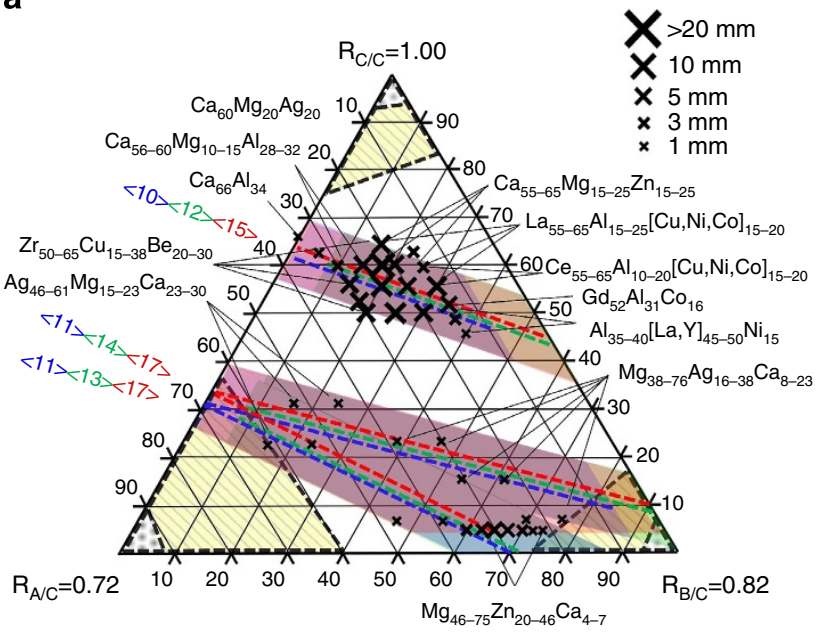

b

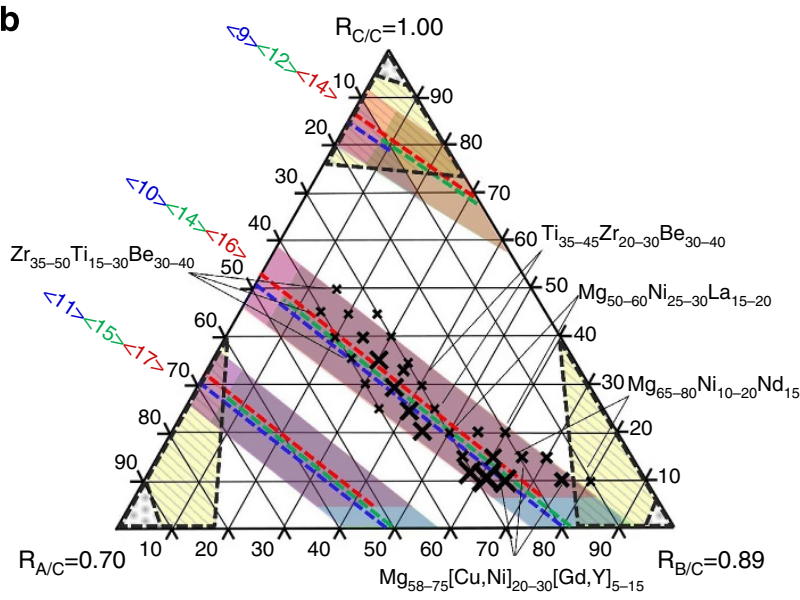

C

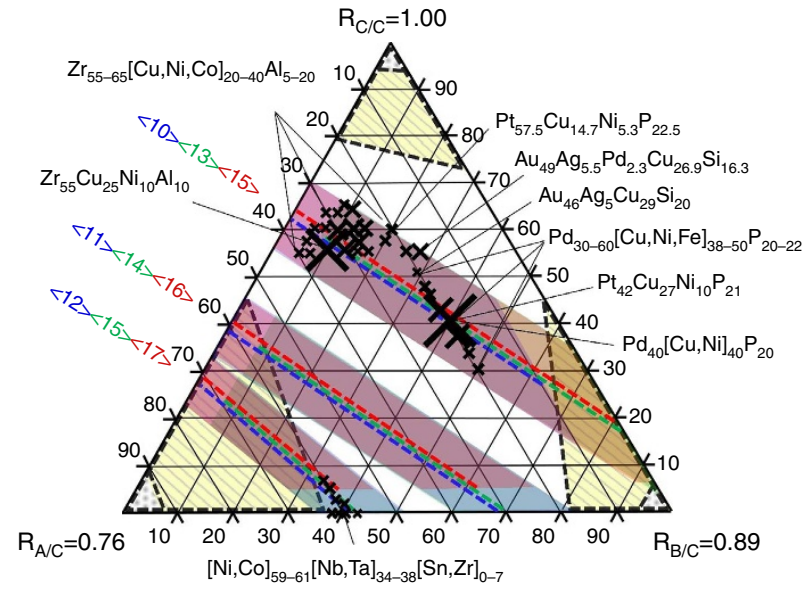

d

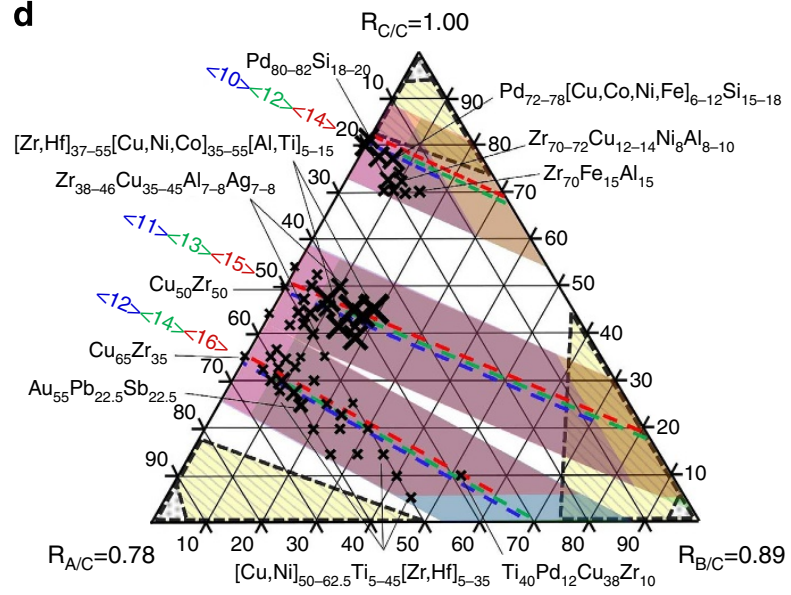

Figure 2 | Ternary diagrams indicating simultaneous efficient packing $(P=100 \pm 2 \%)$ of A- (blue-dashed lines and shading), B- (green-dashed lines and shading) and $\mathbf{C}$ - (red-dashed lines and shading) centred clusters at fixed $<\mathbf{Z}_{\mathbf{A}, \text { tot }}>,<\mathbf{Z}_{\mathbf{B}, \text { tot }}>,<\mathbf{Z}_{\mathbf{C} \text {,tot }}>$ for different radius ratios. (a) $R_{\mathrm{A} / \mathrm{C}}=0.72$, $R_{\mathrm{B} / \mathrm{C}}=0.82 ;(\mathbf{b}) R_{\mathrm{A} / \mathrm{C}}=0.70, R_{\mathrm{B} / \mathrm{C}}=0.89 ;(\mathbf{c}) R_{\mathrm{A} / \mathrm{C}}=0.76, R_{\mathrm{B} / \mathrm{C}}=0.89$ and (d) $R_{\mathrm{A} / \mathrm{C}}=0.78, R_{\mathrm{B} / \mathrm{C}}=0.89$. Exclusion zones based on binary limits are indicated in yellow. Reported BMG compositions (black crosses) are also shown. Data are taken from ref. 52. The atom radii used in the present work are given in Supplementary Table 1.

Simultaneous efficient packing and higher order metallic glasses. We extend analysis to structural quaternary and quinary BMGs-glasses with four or five different atom sizes, respectively, and with as many as seven different elements. Alloys from common quaternary and quinary systems (Supplementary Tables 5 and 6) were used to validate the present ideas. The packing efficiencies of considered glasses all have $\bar{P}=100 \pm 3 \%$. It's difficult to visualize and plot results for quaternary and quinary glasses as was done in Figs 1 and 2 for binary and ternary glasses (Supplementary Note 5 and Supplementary Fig. 4). We plot glass thickness versus $\bar{P}$ for quaternary glasses made of the same elements. Comparisons are shown in Fig. 3 for $\mathrm{Zr}-\mathrm{Ti}-[\mathrm{Cu}, \mathrm{Ni}]-\mathrm{Be}$ and $\mathrm{Mg}-\mathrm{Cu}-\mathrm{Ag}-\mathrm{Gd}$. The results are generally the same as for ternaries-BMGs occur when $\bar{P}=100 \pm 2 \%$ and the best GFA is achieved when $\bar{P}$ is closest to $100 \%$.

Challenging new ideas. Equal-sized spheres are frustrated in three dimensions, so that packing is non-ideal around every atom ${ }^{42}$. Thus, the distance between symmetrically-placed spheres in the first shell of an icosahedron is 5\% larger than the distance to the icosahedron centre. This frustration can be overcome by packing tetrahedra of equal-sized hyperspheres on the curved surface of a four-dimensional sphere ${ }^{42,43}$, but adding unequal spheres is a much simpler three-dimensional approach to reduce frustration. For example, the gaps in an icosahedron disappear when the central sphere has a radius that is 0.9022 that of the surrounding spheres, eliminating packing frustration around the central sphere. Structures built from such efficiently packed clusters are more efficiently packed than equal-sized spheres but remain frustrated, since packing around the first shell atoms is still inefficient. This frustration is apparent by the gaps between clusters-called $\beta$ and $\gamma$ sites in the ECP model. In principle, packing frustration can be further reduced by filling $\beta$ and $\gamma$ sites, but these sites are typically smaller than metallic atoms so that filling these sites pushes the surrounding clusters apart and actually decreases global packing efficiency ${ }^{22}$. Thus, unequal spheres can reduce packing frustration relative to systems of equal-sized spheres, but most atoms remain inefficiently packed. This example uses iscosahedra-the same is true for structures of efficiently packed clusters with different total coordination numbers.

Here we further reduce packing frustration and increase global packing efficiency by establishing the specific conditions for efficient packing around all atoms simultaneously in systems of unequal spheres. Simply stated, if every atom is efficiently packed locally, then the structure may be more efficiently packed globally. This becomes apparent by realizing that atoms in the first shell of one efficiently packed cluster are the centres for other 


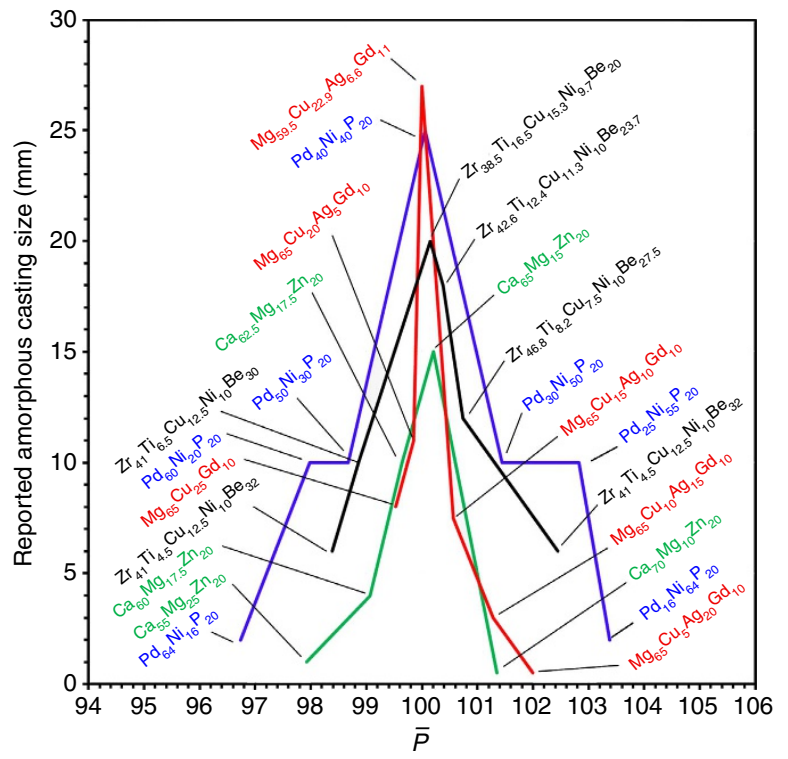

Figure 3 | Reported maximum amorphous thickness versus the mean packing efficiency around all atoms in the structure, $\bar{P}$. Data are shown for several ternary and quaternary glasses. The maximum thickness is found when $\bar{P} \cong 100 \%$ for each of the glasses. The data are taken from refs 53-60.

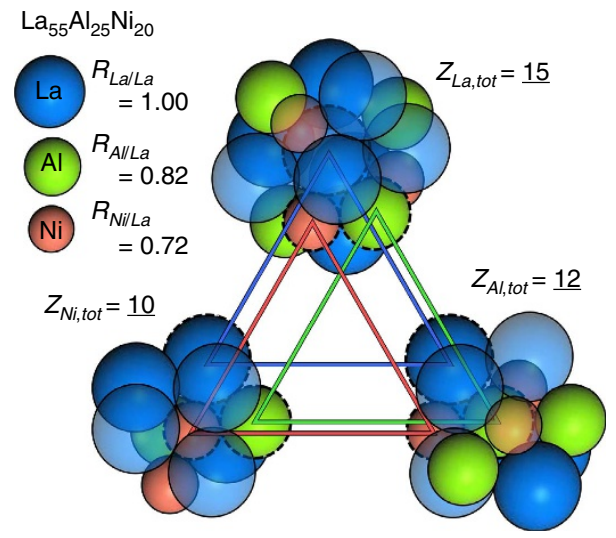

Figure 4 | Three efficiently packed, inter-penetrating, self-consistent clusters in the $\mathbf{A l}_{\mathbf{2 5}} \mathbf{L a}_{\mathbf{5}} \mathbf{N i}_{\mathbf{2 0}} \mathbf{B M G}$. The three atoms outlined by dashed lines and connected by triangles are each the centres of one cluster and are in the first shells of the other two clusters, and so are common to all three clusters. The partial and total coordination numbers are: $Z_{\text {AIAI }}=2, Z_{\text {AlLa }}=7$, $Z_{\mathrm{AINi}}=3, Z_{\mathrm{Al}, \text { tot }}=12$ for the Al-centred cluster; $Z_{\mathrm{LaAl}}=4, Z_{\mathrm{LaLa}}=8$, $Z_{\mathrm{LaNi}}=3, Z_{\mathrm{La}, \text { tot }}=15$ for La-centred clusters; and $Z_{\mathrm{NiAl}}=3, Z_{\mathrm{NiLa}}=6$, $Z_{\mathrm{NiNi}}=1, Z_{\mathrm{Ni}, \text { tot }}=10$ for $\mathrm{Ni}$-centred clusters. These partial coordination numbers are self-consistent, allowing clusters to inter-penetrate with local (cluster) compositions that equal the bulk composition. The relative atom sizes combine with the glass composition and partial coordination numbers to give efficient local packing around all three atom species simultaneously.

efficiently packed clusters (Fig. 4). Simultaneous efficient packing and self-consistency are achieved only on average throughout the structure, since some variability in actual partial coordination numbers, and hence in local packing efficiency, is expected due to kinetic constraints. Using atomic volumes and measured densities, global packing fractions above 0.70 and as high as 0.76 are typical for the most stable binary metallic glasses ${ }^{22}$. The face-centred cubic (fcc) cluster-packing scheme of the ECP model is still an essential feature, since it gives the medium-range atomic order observed in metallic glasses ${ }^{18,21,44}$.
Another advance is a description of the origin and impact of compositional frustration in metallic glasses. Compositional frustration cannot be avoided in binary glasses due to the limited degrees of freedom, and structures that minimize this frustration give the best binary glasses. Extra degrees of freedom in structures with three or more different atom sizes overcome this limitation, so that the composition around all atom types can simultaneously match the bulk composition. The GFA of ternary and higher order glasses is consequently improved. While compositional frustration is not required in complex glasses, it may nevertheless exist due to kinetic constraints from quenching.

The present work introduces new ways to think of metallic glass structures. The ECP model has the simple view that an atom occupies either a solute site at a cluster centre $(\alpha, \beta$ or $\gamma)$ or a solvent site in the cluster first shell $(\Omega)$. Here we fundamentally change this simple description by showing that an atom satisfies requirements for both of these sites at the same time. Thus, an atom that is the centre of one cluster is also in the first shell of other atoms. While this seems self-evident, none of the earlier structural models were able to formalize this dual identity.

These ideas are illustrated in Fig. 4 for the $\mathrm{Al}_{25} \mathrm{La}_{55} \mathrm{Ni}_{20}$ BMG. The three constituent clusters are all inter-connected and have partial coordination numbers that combine with the relative atom sizes to give efficient local atomic packing. Not only are the partial coordination numbers self-consistent, but their arrangements are also self-consistent. This is seen by careful inspection of Fig. 4, which shows that any atom site common to two clusters is occupied by the same atom. Figure 4 also illustrates the surprising result that the preferred SRO around each atom type (reflected by partial coordination numbers and cluster composition) matches the bulk composition. This is unusual, since strong SRO is usually associated with chemical heterogeneity. For example, the local solute concentrations of metalloid-centred clusters in metalmetalloid glasses are typically half the bulk concentration. Here we show that strong SRO is achieved with essentially no local chemical heterogeneity in ternary and more complex glasses. Figure 4 illustrates the elegant inter-connections that allow structures to achieve this challenging set of conditions simultaneously.

Structure, kinetics and chemistry. The present work seems to suggest that GFA can be predicted without considering kinetics. A more robust interpretation is that structure and kinetics are tightly linked-efficiently packed structures are expected to have reduced kinetics and fragility. This has previously been demonstrated $^{35}$, but a quantitative connection between structure and kinetics is still missing. A clue is offered by studies on $\mathrm{Cu}-\mathrm{Zr}$ metallic glasses-packing efficiency (density) was found to be important in defining compositions with best GFA ${ }^{45}$. Subsequent analysis suggested that other properties such as expansivity are important ${ }^{46}$, but more recent work strengthens the connection between structure and kinetics by demonstrating a direct relationship between structural ordering and kinetic fragilities in metallic glasses ${ }^{47}$. This connection between atom sizes and kinetics supports the foresight of $\mathrm{Cahn}^{48}$, a wellrespected metallic glass researcher and a pioneer in establishing the field of materials science, who predicted that, "simple geometry. . . atomic sizes. . . will prove to be the main criterion that in various subtle ways incorporates the others". The present work is also able to explain the positive effect of small additions, 4-7 atom \%, of large atoms on GFA (Supplementary Note 6).

Chemistry is expected to have a direct impact on GFA, since structures of chemically distinct atoms can have significantly different GFA. For example, BMGs form in the $\mathrm{Zr}-\mathrm{Cu}$ system but not in $\mathrm{Zr}-\mathrm{Ni}$. Since $\mathrm{Cu}$ and $\mathrm{Ni}$ atoms are essentially the same size, 
this GFA difference is attributed to a chemical effect ${ }^{49}$. The full predictive power of the present model has therefore not yet been achieved, since it predicts the same GFA of structures regardless of their chemical make-up. Nevertheless, the present work gives a major new capability that is orders of magnitude more effective than current trial-and-error methods. It gives a necessary condition for good GFA, since every BMG we have compared against our model satisfies the present constraints. But it is not sufficient-a clear description of the chemical contribution is needed for a fully predictive model. The specific nature of this chemical effect remains an important, unsolved problem.

The present work resolves a seminal question in metallic glasses by establishing important details of the structures, derived from relative atom sizes and concentrations, needed to form BMGs. We identify new structural defects that significantly limit binary BMGs but have a less dramatic effect in more complex glasses. We show that BMGs require efficient local packing around all atom species and show how this is accomplished. Structural self-consistency gives constraints that are met by only a limited set of binary glass structures, but additional degrees of freedom in higher order systems dramatically expand the number of BMGs. The present model thus gives significant progress towards the long-sought goal of a predictive capability for the most stable metallic glasses. These conditions are necessary but not sufficient and some feature is missing-this is suggested to be a chemical contribution that forms the remaining seminal question in metallic glass stability. And while some of the connections between structure, free volume, fragility, viscosity and GFA are emerging, a more quantitative connection between these features is still desired.

\section{Methods}

Critical concentration of super-substitutional defects. Consider A and B atoms in a face-centred cubic (fcc) crystal ${ }^{33,34}$ that competes with the metallic glass, where $\mathrm{B}$ is the minority (solute) species. A solute atom can replace $N>1$ solvent atoms when it is sufficiently large. For example, a tetrahedron of solvents $(N=4)$ leaves a symmetric space that can be filled by a larger B atom. In addition to this tetrahedral 'super-substitutional' defect, three other sufficiently symmetric defects occur within the radius ratios relevant for metallic glasses. These are listed in Supplementary Table 2, along with the radius ratios that just fill these super-substitutional defects.

Foppl notation ${ }^{50}$ gives a simple description of each defect configuration. As used here, $\left(n_{1}, n_{2} \ldots\right)_{h k l}$ is the number of atoms, $n_{\mathrm{i}}$, in successive parallel $h, k, l$ planes of an fcc structure and $\Sigma n_{i}=N$. Critical defect concentrations are calculated as in ref. 34. The strain given by each defect vanishes and the defect concentration, $f_{\mathrm{B}}$, approaches 1 at the $R_{\mathrm{A} / \mathrm{B}}$ values shown. We truncate the defect concentration at $f_{\mathrm{B}}=0.50$ for convenience, the actual value may be different. This analysis gives the atom fraction of $\mathrm{B}$ atoms, $f_{\mathrm{B}}$, which is transformed to $f_{\text {crit }}=1-f_{\mathrm{B}}$ in Fig. 1. A spike in the $f_{\mathrm{B}}$ versus $R_{\mathrm{A} / \mathrm{B}}$ curve near the minimum in $f_{\text {crit }}$ between competing defects is due to partial occupancy of both defects ${ }^{34}$. We eliminate this artifact by assuming only the defect with the lowest strain energy is occupied.

The $N=3$ defect is asymmetric but may also be important. The solute that just fits in this defect has $R_{\mathrm{B} / \mathrm{A}}=(4 / \sqrt{ } 3)-1$ within the plane of the defect and $R_{\mathrm{B} / \mathrm{A}}=1$ normal to the defect plane. This gives an average $R_{\mathrm{B} / \mathrm{A}}$ of $2 / \sqrt{3}$, so that an excluded region is expected near $R_{\mathrm{A} / \mathrm{B}}=\sqrt{3 / 2}=0.866$. The averaging used here is only an approximation, but the result is included in Fig. 1 and Supplementary Fig. 2c,d for completeness.

This approach is for super-substitutional defects that are largely symmetric. We can represent the degree of asymmetry of a super-substitutional defect as the difference between the minimum and maximum sphere radii that can fit in the super-substitutional defect normalized by the size of the host sphere. A divacancy has an asymmetry factor of $100 \%$-this is too asymmetric to be meaningful and such defects are not included here. Super-substitutional defects for clusters of four vacancies (a tetrahedron) and six vacancies (an octahedron) are symmetric and have asymmetry factors of $0 \%$. Super-substitutional defects with 8 and 10 vacancies are nearly symmetric, and the most asymmetric super-substitutional defect used in the present work has three vacancies and an asymmetry factor of $30 \%$.

Radius ratios for A- and B-centred clusters. The effective radius ratio in $i$-centred clusters, $\bar{R}^{i}$, is so that for binary A-B systems

$$
\bar{R}^{\mathrm{A}}=\frac{R_{\mathrm{A} / \mathrm{B}}\left(Z_{\mathrm{A}, \text { tot }}\right)}{R_{\mathrm{A} / \mathrm{B}}\left(Z_{\mathrm{AA}}\right)+\left(Z_{\mathrm{AB}}\right)} \quad \bar{R}^{\mathrm{B}}=\frac{\left(Z_{\mathrm{B}, \text { tot }}\right)}{R_{\mathrm{A} / \mathrm{B}}\left(Z_{\mathrm{BA}}\right)+\left(Z_{\mathrm{BB}}\right)}
$$

The packing efficiency of atoms in the first shell of an $i$-centred cluster is ${ }^{30}$

$$
P^{i}=\frac{R_{Z}^{*, i}}{\bar{R}^{i}}
$$

This extends an earlier approach for solute-lean clusters to solute-rich glasses and has been validated elsewhere ${ }^{20,30}$. Combining equation $(7,8)$ gives the nominal radius ratios of $\mathrm{A}$ - and $\mathrm{B}$-centred clusters in equation (2).

Simultaneous solution of structural self-consistency: binary glasses. We combine equations (2) and (3) to give

$$
\left(Z_{\mathrm{AB}}\right)\left(Z_{\mathrm{BA}}\right)=\left(X^{\mathrm{A}}-Z_{\mathrm{AA}}\right)\left(X^{\mathrm{B}}-Z_{\mathrm{BB}}\right)=\left(\{\underline{\mathrm{A}}\}+Z_{\mathrm{AB}}\right)\left(\{\underline{\mathrm{B}}\}+Z_{\mathrm{BA}}\right)
$$

where $\{\underline{i}\}=\left(X^{i}-Z_{i, \text { tot }}\right)$ and $X^{i}=\left(P^{i}\right)\left(Z_{i, \text { tot }}\right) / R_{Z}^{*, i}$. Expanding the product gives

$$
\{\underline{\mathrm{A}}\}\left(Z_{\mathrm{BA}}\right)+\{\underline{\mathrm{B}}\}\left(Z_{\mathrm{AB}}\right)=-\{\underline{\mathrm{A}}\}\{\underline{\mathrm{B}}\}
$$

Two solutions exist for each intersection - one where $f_{\mathrm{A}}^{\mathrm{G}}=f_{\mathrm{A}}^{\mathrm{A}}$ (A-reference solution) and one where $f_{\mathrm{A}}^{\mathrm{G}}=f_{\mathrm{A}}^{\mathrm{B}}$ (B-reference solution). For the A-reference solution, we substitute $f_{\mathrm{A}}^{\mathrm{A}}$ from equation (1) into equation (4) and rearrange terms to give

$$
Z_{\mathrm{BA}}=\left(Z_{\mathrm{A}, \text { tot }}+\lambda\right)-Z_{\mathrm{AB}}
$$

Rearranging equation (10) gives

$$
Z_{\mathrm{BA}}=-\left[\{\underline{\mathrm{B}}\}+\frac{\{\underline{\mathrm{B}}\}}{\{\underline{\mathrm{A}}\}}\left(Z_{\mathrm{AB}}\right)\right]
$$

Setting equation (11) and (12) equal and solving for $Z_{\mathrm{AB}}$ gives

$$
Z_{\mathrm{AB}}=\frac{\left(Z_{\mathrm{A}, \text { tot }}+\lambda\right)+\{\underline{\mathrm{B}}\}}{1-\{\underline{\mathrm{B}}\} /\{\underline{\mathrm{A}}\}}
$$

Using $\lambda=2, Z_{\mathrm{AB}}$ gives $f_{\mathrm{A}}^{\mathrm{A}}$ and $R_{\mathrm{A} / \mathrm{B}}^{\mathrm{A}}$; we determine $Z_{\mathrm{BA}}$ from equation (4) and calculate $f_{\mathrm{A}}^{\mathrm{B}}$ from equation (1).

The B-reference solution follows a similar approach to give the final solution,

$$
Z_{\mathrm{BA}}=\frac{\left(Z_{\mathrm{B}, \mathrm{tot}}+\lambda\right)+\{\underline{\mathrm{A}}\}}{1-\{\underline{\mathrm{A}}\} /\{\underline{\mathrm{B}}\}}
$$

Efficient packing in ternary metallic glasses. From equation (6), the effective radius ratios around $\mathrm{A}, \mathrm{B}$ and $\mathrm{C}$ atoms are

$$
\begin{aligned}
& \bar{R}^{\mathrm{A}}=\frac{\left(r_{\mathrm{A}}\right)\left(Z_{\mathrm{A}, \text { tot }}\right)}{\left(r_{\mathrm{A}}\right)\left(Z_{\mathrm{AA}}\right)+\left(r_{\mathrm{B}}\right)\left(Z_{\mathrm{AB}}\right)+\left(r_{\mathrm{C}}\right)\left(Z_{\mathrm{AC}}\right)} \\
& =\frac{R_{\mathrm{A} / \mathrm{C}}\left(Z_{\mathrm{A}, \text { tot }}\right)}{\left(R_{\mathrm{A} / \mathrm{C}}\right)\left(Z_{\mathrm{AA}}\right)+\left(R_{\mathrm{B} / \mathrm{C}}\right)\left(Z_{\mathrm{AB}}\right)+\left(Z_{\mathrm{AC}}\right)} \\
& \bar{R}^{\mathrm{B}}=\frac{\left(r_{\mathrm{B}}\right)\left(Z_{\mathrm{B}, \text { tot }}\right)}{\left(r_{\mathrm{A}}\right)\left(Z_{\mathrm{BA}}\right)+\left(r_{\mathrm{B}}\right)\left(Z_{\mathrm{BB}}\right)+\left(r_{\mathrm{C}}\right)\left(Z_{\mathrm{BC}}\right)} \\
& =\frac{\left(R_{\mathrm{B} / \mathrm{C}}\right)\left(Z_{\mathrm{B}, \text { tot }}\right)}{\left(R_{\mathrm{A} / \mathrm{C}}\right)\left(Z_{\mathrm{BA}}\right)+\left(R_{\mathrm{B} / \mathrm{C}}\right)\left(Z_{\mathrm{BB}}\right)+\left(Z_{\mathrm{BC}}\right)} \\
& \bar{R}^{\mathrm{C}}=\frac{\left(r_{\mathrm{C}}\right)\left(Z_{\mathrm{C}, \text { tot }}\right)}{\left(r_{\mathrm{A}}\right)\left(Z_{\mathrm{CA}}\right)+\left(r_{\mathrm{B}}\right)\left(Z_{\mathrm{CB}}\right)+\left(r_{\mathrm{C}}\right)\left(Z_{\mathrm{CC}}\right)} \\
& =\frac{\left(Z_{\mathrm{C}, \text { tot }}\right)}{\left(R_{\mathrm{A} / \mathrm{C}}\right)\left(Z_{\mathrm{CA}}\right)+\left(R_{\mathrm{B} / \mathrm{C}}\right)\left(Z_{\mathrm{CB}}\right)+\left(Z_{\mathrm{CC}}\right)}
\end{aligned}
$$

where $r_{\mathrm{A}}<r_{\mathrm{B}}<r_{\mathrm{C}}$, and $R_{i / j}=r_{i} / r_{j}$. Combining $\left(P^{i}=\frac{R_{2}^{* i,}}{R^{i}}\right)$ and rearranging terms gives

$$
\begin{gathered}
\left(R_{\mathrm{A} / \mathrm{C}}\right)\left(Z_{\mathrm{AA}}\right)+\left(R_{\mathrm{B} / \mathrm{C}}\right)\left(Z_{\mathrm{AB}}\right)+\left(Z_{\mathrm{AC}}\right)=\frac{\left(R_{\mathrm{A} / \mathrm{C}}\right)\left(Z_{\mathrm{A}, \text { tot }}\right)\left(P^{y}\right)}{R_{\mathrm{Z}_{\mathrm{A}, \text { tot }}}} \\
\left(R_{\mathrm{A} / \mathrm{C}}\right)\left(Z_{\mathrm{BA}}\right)+\left(R_{\mathrm{B} / \mathrm{C}}\right)\left(Z_{\mathrm{BB}}\right)+\left(Z_{\mathrm{BC}}\right)=\frac{\left(R_{\mathrm{B} / \mathrm{C}}\right)\left(Z_{\mathrm{B}, \text { tot }}\right)\left(P^{\mathrm{B}}\right)}{R_{Z_{\mathrm{B}, \text { tot }}^{*}}^{\mathrm{B}}} \\
\left(R_{\mathrm{A} / \mathrm{C}}\right)\left(Z_{\mathrm{CA}}\right)+\left(R_{\mathrm{B} / \mathrm{C}}\right)\left(Z_{\mathrm{CB}}\right)+\left(Z_{\mathrm{CC}}\right)=\frac{\left(Z_{\mathrm{C}, \text { tot }}\right)\left(P^{\mathrm{C}}\right)}{R_{Z_{\mathrm{C}, \text { tot }}^{*}, \mathrm{C}}}
\end{gathered}
$$


From equation (1)

$$
\begin{gathered}
f_{\mathrm{A}}^{\mathrm{A}}+f_{\mathrm{B}}^{\mathrm{A}}+f_{\mathrm{C}}^{\mathrm{A}}=\frac{Z_{\mathrm{AA}}+\lambda}{Z_{\mathrm{A}, \text { tot }}+\lambda}+\frac{Z_{\mathrm{AB}}}{Z_{\mathrm{A}, \text { tot }}+\lambda}+\frac{Z_{\mathrm{AC}}}{Z_{\mathrm{A}, \text { tot }}+\lambda}=1 \\
f_{\mathrm{A}}^{\mathrm{B}}+f_{\mathrm{B}}^{\mathrm{B}}+f_{\mathrm{C}}^{\mathrm{B}}=\frac{Z_{\mathrm{BA}}}{Z_{\mathrm{B}, \text { tot }}+\lambda}+\frac{Z_{\mathrm{BB}}+\lambda}{Z_{\mathrm{B}, \text { tot }}+\lambda}+\frac{Z_{\mathrm{BC}}}{Z_{\mathrm{B}, \text { tot }}+\lambda}=1 \\
f_{\mathrm{A}}^{\mathrm{C}}+f_{\mathrm{B}}^{\mathrm{C}}+f_{\mathrm{C}}^{\mathrm{C}}=\frac{Z_{\mathrm{CA}}}{Z_{\mathrm{C}, \text { tot }}+\lambda}+\frac{Z_{\mathrm{CB}}}{Z_{\mathrm{C}, \text { tot }}+\lambda}+\frac{Z_{\mathrm{CC}}+\lambda}{Z_{\mathrm{C}, \text { tot }}+\lambda}=1
\end{gathered}
$$

Efficiently packed clusters in the $\mathrm{A}-\mathrm{B}-\mathrm{C}$ ternary diagram have compositions along specific lines (Fig. 2). For A-centred clusters, the efficient packing line intercepts the $\mathrm{A}-\mathrm{C}$ binary when $Z_{\mathrm{AB}}=0$ and $Z_{\mathrm{AA}}=Z_{\mathrm{A}, \text { tot }}-Z_{\mathrm{AC}}$. Inserting these into equation (18) and rearranging terms gives

$$
Z_{\mathrm{AC}}=\frac{\left(R_{\mathrm{A} / \mathrm{C}}\right)\left(Z_{\mathrm{A}, \text { tot }}\right)}{\left(1-R_{\mathrm{A} / \mathrm{C}}\right)}\left[\frac{P^{\mathrm{A}}}{R_{Z_{\mathrm{A}, \text { tot }}^{*} \mathrm{~A}}^{\mathrm{A}}}-1\right]
$$

Combining with equation (21) and using $f_{\mathrm{A}}^{\mathrm{A}}=1-f_{\mathrm{C}}^{\mathrm{A}}$ gives

$$
f_{\mathrm{A}}^{\mathrm{A}}=f_{\mathrm{A}-\mathrm{C}}^{\mathrm{A}}=1-\frac{\left(R_{\mathrm{A} / \mathrm{C}}\right)\left(Z_{\mathrm{A}, \text { tot }}\right)}{\left(1-R_{\mathrm{A} / \mathrm{C}}\right)}\left[\frac{P^{\mathrm{A}}}{R_{Z_{\mathrm{A}, \text { tot }}^{*} \mathrm{~A}}}-1\right]\left[\frac{1}{Z_{\mathrm{A}, \text { tot }}+\lambda}\right]
$$

These values are given as $f_{A-C}^{A}$ in Supplementary Table 3, where the superscript is the atom at the cluster centre, the subscript is the binary line contacted by the intercept and the first letter in the subscript is the atom for which the concentration is given. Following a similar approach, efficiently packed A-centred clusters intercept the B-A binary boundary at

$$
f_{\mathrm{B}-\mathrm{A}}^{\mathrm{A}}=1-\left[\frac{\left(R_{\mathrm{A} / \mathrm{C}}\right)\left(Z_{\mathrm{A}, \text { tot }}\right)}{\left(R_{\mathrm{B} / \mathrm{C}}-R_{\mathrm{A} / \mathrm{C}}\right)}\right]\left[\frac{\left(P^{\mathrm{A}}\right)}{R_{Z_{\mathrm{A}, \text { tot }}^{* A}}^{*,}}-1\right]\left[\frac{1}{Z_{\mathrm{A}, \text { tot }}+\lambda}\right]
$$

Using the same approach, intercepts for efficiently packed B-centred clusters are given by

$$
\begin{gathered}
f_{\mathrm{B}-\mathrm{A}}^{\mathrm{B}}=1-\left[\frac{\left(R_{\mathrm{B} / \mathrm{C}}\right)\left(Z_{\mathrm{B}, \text { tot }}\right)}{\left(R_{\mathrm{A} / \mathrm{C}}-R_{\mathrm{B} / \mathrm{C}}\right)}\right]\left[\frac{P^{\mathrm{B}}}{R_{\mathrm{Z}_{\mathrm{B}, \text { tot }}^{*, \mathrm{~B}}}}-1\right]\left[\frac{1}{Z_{\mathrm{B}, \text { tot }}+\lambda}\right] \\
f_{\mathrm{CB}}^{\mathrm{B}}=\left[\frac{\left(R_{\mathrm{B} / \mathrm{C}}\right)\left(Z_{\mathrm{B}, \text { tot }}\right)}{\left(1-R_{\mathrm{B} / \mathrm{C}}\right)}\right]\left[\frac{P^{\mathrm{B}}}{R_{Z_{\mathrm{B}, \text { tot }}^{*, \mathrm{~B}}}}-1\right]\left[\frac{1}{Z_{\mathrm{B}, \text { tot }}+\lambda}\right]
\end{gathered}
$$

Finally, the intercepts for efficiently packed C-centred clusters are determined from

$$
\begin{aligned}
& f_{\mathrm{AC}}^{\mathrm{C}}=\left[\frac{\left(Z_{\mathrm{C}, \text { tot }}\right)}{\left(R_{\mathrm{A} / \mathrm{C}}-1\right)}\right]\left[\frac{P^{\mathrm{C}}}{R_{\mathrm{Z}_{\mathrm{C}, \text { tot }}^{*}}^{*}}-1\right]\left[\frac{1}{Z_{\mathrm{C}, \text { tot }}+\lambda}\right] \\
& f_{C-B}^{C}=1-\left[\frac{\left(Z_{C, \text { tot }}\right)}{\left(R_{B / C}-1\right)}\right]\left[\frac{P^{C}}{R_{Z_{C, t o t}^{* C}}^{* C}}-1\right]\left[\frac{1}{Z_{C, \text { tot }}+\lambda}\right]
\end{aligned}
$$

For a given $<Z_{\mathrm{A}, \text { tot }}, Z_{\mathrm{B}, \text { tot }}, Z_{\mathrm{C}, \text { tot }}>$ structure, the efficient packing lines for $\mathrm{A}$ - and $\mathrm{C}$-centred clusters both intersect the $\mathrm{A}-\mathrm{C}$ binary boundary at the same composition using the $R_{\mathrm{A} / \mathrm{C}}$ and $R_{\mathrm{B} / \mathrm{C}}$ values in Supplementary Table 3 . The same is true for efficient packing intercepts of A- and B-centred clusters on the A - B binary boundary and of $\mathrm{B}$ - and $\mathrm{C}$-centred clusters on the $\mathrm{B}-\mathrm{C}$ binary boundary. The compositions of A-centred clusters do not intersect the $\mathrm{B}-\mathrm{C}$ binary boundary, $\mathrm{B}$-centred clusters do not intersect the $\mathrm{A}-\mathrm{C}$ boundary and $\mathrm{C}$-centred clusters do not intersect the $\mathrm{A}-\mathrm{B}$ boundary, since the minimum $i$ atom fraction for structures of $i$-centred clusters is $f_{i}=1 /\left(Z_{i, \text { tot }}+\lambda\right)$. At these minimum compositions, the $j$ atom fractions of $i$-centred clusters, $f_{j}^{i}$, are

$$
\begin{gathered}
f_{\mathrm{C}}^{\mathrm{A}}=\left[\frac{Z_{\mathrm{A}, \text { tot }}}{Z_{\mathrm{A}, \text { tot }}+\lambda}\right]\left[\frac{\left(R_{\mathrm{A} / \mathrm{C}}\right)\left(P^{\mathrm{A}}\right)}{R_{\mathrm{Z}_{\mathrm{A}, \text { tot }}^{*, \mathrm{~A}}}}-R_{\mathrm{B} / \mathrm{C}}\right]\left[\frac{1}{\left(1-R_{\mathrm{B} / \mathrm{C}}\right)}\right] \\
f_{\mathrm{A}}^{\mathrm{B}}=\left[\frac{Z_{\mathrm{B}, \text { tot }}}{Z_{\mathrm{B}, \text { tot }}+\lambda}\right]\left[\frac{\left(R_{\mathrm{B} / \mathrm{C}}\right)\left(P^{\mathrm{B}}\right)}{R_{\mathrm{Z}_{\mathrm{B}, \text { tot }}^{*} \mathrm{~B}}}-1\right]\left[\frac{1}{\left(R_{\mathrm{A} / \mathrm{C}}-1\right)}\right] \\
f_{\mathrm{B}}^{\mathrm{C}}=\left[\frac{Z_{\mathrm{C}, \text { tot }}}{Z_{\mathrm{C}, \text { tot }}+\lambda}\right]\left[\frac{P^{\mathrm{C}}}{R_{Z_{\mathrm{C}, \text { tot }}^{*, \mathrm{C}}}}-R_{\mathrm{A} / \mathrm{C}}\right]\left[\frac{1}{\left(R_{\mathrm{B} / \mathrm{C}}-R_{\mathrm{A} / \mathrm{C}}\right)}\right]
\end{gathered}
$$

These compositions, together with $f_{i}=1 /\left(Z_{i}\right.$, tot $\left.+\lambda\right)$, lie on the efficiently packed lines given by equations (24-30). Thus, all three clusters for each given $<Z_{\mathrm{A} \text {,tot }}$, $Z_{\mathrm{B}, \text { tot }}, Z_{\mathrm{C}, \text { tot }}>$ structure have the same efficiently packed lines. Using $P^{\mathrm{i}}=1, \lambda=1$ and the specific $R_{\mathrm{A} / \mathrm{C}}$ and $R_{\mathrm{B} / \mathrm{C}}$ values from Supplementary Table 3 for each $<Z_{\mathrm{A}, \text { tot }}, Z_{\mathrm{B}, \text { tot }}, Z_{\mathrm{C} \text {,tot }}>$ structure gives the efficient packing intercepts in Fig. 2 and Supplementary Table 3 . The shaded bands of efficient packing are obtained using $P^{i}=0.98$ and $P^{i}=1.02$.
Structural self-consistency: ternary, quaternary and quinary glasses. Structural self-consistency provides three equalities in ternary systems

$$
\frac{Z_{\mathrm{AB}}}{Z_{\mathrm{BA}}}=\frac{f_{\mathrm{B}}^{\mathrm{G}}}{f_{\mathrm{A}}^{\mathrm{G}}} \quad \frac{Z_{\mathrm{BC}}}{Z_{\mathrm{CB}}}=\frac{f_{\mathrm{C}}^{\mathrm{G}}}{f_{\mathrm{B}}^{\mathrm{G}}} \quad \frac{Z_{\mathrm{CA}}}{Z_{\mathrm{AC}}}=\frac{f_{\mathrm{A}}^{\mathrm{G}}}{f_{\mathrm{C}}^{\mathrm{G}}}
$$

This gives the surprising result

$$
\left(\frac{Z_{\mathrm{AB}}}{Z_{\mathrm{BA}}}\right)\left(\frac{Z_{\mathrm{BC}}}{Z_{\mathrm{CB}}}\right)\left(\frac{Z_{\mathrm{CA}}}{Z_{\mathrm{AC}}}\right)=\left(\frac{f_{\mathrm{B}}^{\mathrm{G}}}{f_{\mathrm{A}}^{\mathrm{G}}}\right)\left(\frac{f_{\mathrm{C}}^{\mathrm{G}}}{f_{\mathrm{B}}^{\mathrm{G}}}\right)\left(\frac{f_{\mathrm{A}}^{\mathrm{G}}}{f_{\mathrm{C}}^{\mathrm{G}}}\right)=1
$$

Using the $Z_{i j}$ values in equation (34) for the glass compositions via equation (1) gives the same result. Thus, self-consistency is always satisfied in ternary glasses when the cluster composition is the same as the glass composition. Following a similar approach for quaternary alloys,

$$
\left(\frac{Z_{\mathrm{AB}}}{Z_{\mathrm{BA}}}\right)\left(\frac{Z_{\mathrm{BC}}}{Z_{\mathrm{CB}}}\right)\left(\frac{Z_{\mathrm{CD}}}{Z_{\mathrm{DC}}}\right)\left(\frac{Z_{\mathrm{DA}}}{Z_{\mathrm{AD}}}\right)=\left(\frac{f_{\mathrm{B}}}{f_{\mathrm{A}}}\right)\left(\frac{f_{\mathrm{C}}}{f_{\mathrm{B}}}\right)\left(\frac{f_{\mathrm{D}}}{f_{\mathrm{C}}}\right)\left(\frac{f_{\mathrm{A}}}{f_{\mathrm{D}}}\right)=1
$$

There are two solutions to self-consistency for quinary glasses

$$
\begin{gathered}
\left(\frac{Z_{\mathrm{AB}}}{Z_{\mathrm{BA}}}\right)\left(\frac{Z_{\mathrm{BC}}}{Z_{\mathrm{CB}}}\right)\left(\frac{Z_{\mathrm{CD}}}{Z_{\mathrm{DC}}}\right)\left(\frac{Z_{\mathrm{DE}}}{Z_{\mathrm{ED}}}\right)\left(\frac{Z_{\mathrm{EA}}}{Z_{\mathrm{AE}}}\right)=\left(\frac{f_{\mathrm{B}}}{f_{\mathrm{A}}}\right)\left(\frac{f_{\mathrm{C}}}{f_{\mathrm{B}}}\right)\left(\frac{f_{\mathrm{D}}}{f_{\mathrm{C}}}\right)\left(\frac{f_{\mathrm{E}}}{f_{\mathrm{D}}}\right)\left(\frac{f_{\mathrm{A}}}{f_{\mathrm{E}}}\right)=1 \\
\left(\frac{Z_{\mathrm{AC}}}{Z_{\mathrm{CA}}}\right)\left(\frac{Z_{\mathrm{BD}}}{Z_{\mathrm{DB}}}\right)\left(\frac{Z_{\mathrm{CE}}}{Z_{\mathrm{EC}}}\right)\left(\frac{Z_{\mathrm{DA}}}{Z_{\mathrm{AD}}}\right)\left(\frac{Z_{\mathrm{EB}}}{Z_{\mathrm{BE}}}\right)=\left(\frac{f_{\mathrm{C}}}{f_{\mathrm{A}}}\right)\left(\frac{f_{\mathrm{D}}}{f_{\mathrm{B}}}\right)\left(\frac{f_{\mathrm{E}}}{f_{\mathrm{C}}}\right)\left(\frac{f_{\mathrm{A}}}{f_{\mathrm{D}}}\right)\left(\frac{f_{\mathrm{B}}}{f_{\mathrm{E}}}\right)=1
\end{gathered}
$$

As for ternary glasses, self-consistency is always satisfied in quaternary and quinary glasses when the cluster composition is the same as the glass composition.

\section{References}

1. Klement, W., Willens, R. H. \& Duwez, P. Non-crystalline structure in solidified gold-silicon alloys. Nature 187, 869-870 (1960).

2. Bernal, J. D. Geometry of the structure of monatomic liquids. Nature 185, 68-70 (1960).

3. Bernal, J. D. The structure of liquids. Proc. R. Soc. A 280, 299-322 (1964).

4. Bernal, J. D. \& Mason, J. Co-ordination of randomly packed spheres. Nature 188, 910-911 (1960).

5. Polk, D. E. Structural model for amorphous metallic alloys. Scr. Mater. 4, 117-122 (1970).

6. Polk, D. E. The structure of glassy metallic alloys. Acta Metall. 20, 485-491 (1972).

7. Frost, H. J. Cavities in dense random packings. Acta Metall. 30, 889-904 (1982)

8. Gaskell, P. H. A new structural model for transition metal-metalloid glasses. Nature 276, 484-485 (1978).

9. Dubois, J. M., Gaskell, P. H. \& Caer, G. L. A model for the structure of metallic glasses based on chemical twinning. Proc. R. Soc. A 402, 323-357 (1985).

10. Gaskell, P. H. A new structural model for amorphous transition metal silicides, borides, phosphides and carbides. J. Non Cryst. Solids 32, 207-224 (1979).

11. Jin, O., Schwarz, R. B., Alamgir, F. M. \& Jain, H. in Materials Research Society Symposium Proceedings. (eds Gonis, A., Turchi, P.E.A \& Ardell, A.J.) 277-282 (Warrendale, PA, USA).

12. Ramachandrarao, P. On glass formation in metal-metal systems. Z. Metallkd. 71, 172-177 (1980).

13. Shen, T. D., Harms, U. \& Schwarz, R. B. Correlation between the volume change during crystallization and the thermal stability of supercooled liquids. Appl. Phys. Lett. 83, 4512-4514 (2003).

14. Yavari, A. R. Small volume change on melting as a new criterion for easy formation of metallic glasses. Phys. Lett. 95A, 165-168 (1983).

15. Gaskell, P.H. in Topics in Applied Physics, Glassy Metals II Vol. 53 (eds Beck, H. \& Guntherodt, H.-J.) 5-49 (Springer-Verlag, 1983).

16. Gaskell, P.h. in Materials Science and Technology Vol. 9 (ed. Zarzycki, J.) 175-278 (VCH, 1991).

17. Lamparter, P. \& Steeb, S. in Materials Science and Technology: A Comprehensive Treatment (ed Gerold, V.) 217-288 (VCH, 1993).

18. Miracle, D. B. A structural model for metallic glasses. Nat. Mater. 3, 697-702 (2004).

19. Sheng, H. W., Luo, W. K., Alamgir, F. M., Bai, J. M. \& Ma, E. Atomic packing and short-to-medium range order in metallic glasses. Nature 439, 419-425 (2006).

20. Miracle, D. B., Laws, K. J., Senkov, O. N. \& Wilks, G. B. Partial coordination numbers in binary metallic glasses. Metall. Mater. Trans. 43A, 2649-2661 (2012).

21. Miracle, D. B. A physical model for metallic glass structures: an introduction and update. JOM 64, 846-855 (2012).

22. Miracle, D. B. The density and packing fraction of binary metallic glasses. Acta Mater. 61, 3157-3171 (2013).

23. Ma, D. et al. Nearest-neighbor coordination and chemical ordering in multi-component bulk metallic glasses. Appl. Phys. Lett. 90, 211901-211903 (2007).

24. Hirata, A. et al. Direct observation of local atomic order in a metallic glass. Nat. Mater. 10, 28-33 (2011). 
25. Inoue, A., Zhang, T. \& Masumoto, T. Zr-Al-Ni amorphous alloys with high glass transition temperature and significant supercooled liquid region. Mater. Trans. JIM 31, 177-183 (1990).

26. Pekar, A. \& Johnson, W. L. A highly processable metallic glass: $\mathrm{Zr}_{41.2} \mathrm{Ti}_{13.8} \mathrm{Cu}_{12.5} \mathrm{Ni}_{10.0} \mathrm{Be}_{22.5}$. Appl. Phys. Lett. 63, 2342-2344 (1993).

27. Laws, K. J., Shamlaye, K. F., Cao, J. D., Scicluna, J. P. \& Ferry, M. Locating new Mg-based bulk metallic glasses free of rare earth elements. J. Alloys Compd. 542, 105-110 (2012)

28. Laws, K. J., Shamlaye, K. F. \& Ferry, M. Synthesis of Ag-based bulk metallic glass in the Ag-Mg-Ca-[Cu] alloy system. J. Alloys Compd. 513, 10-13 (2012).

29. Laws, K. J., Shamlaye, K. F., Gun, B., Wong, K. \& Ferry, M. The prediction of glass-forming compositions in metallic systems - the development of new bulk metallic glasses. Mater. Sci. Forum 638-642, 1637-1641 (2010).

30. Laws, K. J., Shamlaye, K. F., Wong, K., Gun, B. \& Ferry, M. Prediction of glassforming compositions in metallic systems: copper-based bulk metallic glasses in the Cu-Mg-Ca system. Metall. Mater. Trans. 41A, 1699-1705 (2010).

31. Miracle, D. B., Sanders, W. S. \& Senkov, O. N. The influence of efficient atomic packing on the constitution of metallic glasses. Philos. Mag. A 83, 2409-2428 (2003).

32. Miracle, D. B., Louzguine-Luzgin, D., Louzguina-Luzgina, L. \& Inoue, A. An assessment of binary metallic glasses: correlations between structure, glass forming ability and stability. Int. Mater. Rev. 55, 218-256 (2010).

33. Egami, T. \& Waseda, Y. Atomic size effect on the formability of metallic glasses. J. Non Cryst. Solids 64, 113-134 (1984).

34. Senkov, O. N. \& Miracle, D. B. A topological model for metallic glass formation. J. Non Cryst. Solids 317, 34-39 (2003).

35. Mukherjee, S., Schroers, J., Zhou, Z., Johnson, W. L. \& Rhim, W.-R. Viscosity and specific volume of bulk metallic glass-forming alloys and their correlation with glass forming ability. Acta Mater. 52, 3689-3695 (2004).

36. Miracle, D. B. Efficient local packing in metallic glasses. J. Non Cryst. Solids 242, 89-96 (2004).

37. Cheng, Y. Q. \& Ma, E. Atomic-level structure and structure-property relationship in metallic glasses. Prog. Mater. Sci. 56, 379-473 (2011).

38. Steeb, S. \& Lamparter, P. Structure of binary metallic glasses. J. Non Cryst. Solids 156-158, 24-33 (1993).

39. Gershon, E. Glasses Strong as Steel: A Fast Way to Find the Best http://news.yale.edu/2014/04/13/glasses-strong-steel-fast-way-find-best (2014).

40. Nishiyama, N. et al. The world's biggest glassy alloy ever made. Intermetallics 30, 19-24 (2012).

41. $\mathrm{Na}, \mathrm{J}$. H. et al. Compositional landscape for glass formation in metal alloys. PNAS 111, 9031-9036 (2014).

42. Nelson, D. R. \& Spaepen, F. Polytetrahedral order in condensed matter. Solid State Phys. 42, 1-90 (1989).

43. Coxeter, H. S. M. The problem of packing a number of equal nonoverlapping circles on a sphere. Trans. NY Acad. Sci. Ser. II 24, 320-331 (1962).

44. Miracle, D. B., Greer, A. L. \& Kelton, K. F. Icosahedral and dense random cluster packing in metallic glass structures. J. Non Cryst. Solids 354, 4049-4055 (2008).

45. Li, Y., Guo, Q., Kalb, J. A. \& Thompson, C. V. Matching glass-forming ability with the density of the amorphous phase. Science 322, 1816-1819 (2008).

46. Bendert, J. C., Gangopadhyay, A. K., Mauro, N. A. \& Kelton, K. F. Volume expansion measurements in metallic liquids and their relation to fragility and glass forming ability: an energy landscape interpretation. Phys. Rev. Lett. 109, 1-5 (2012).

47. Mauro, N. A., Blodgett, M., Johnson, M. L., Vogt, A. J. \& Kelton, K. F. A structural signature of liquid fragility. Nat. Commun. 5, 4616 (2014).

48. Cahn, R. W. in Materials Science and Technology Vol. 9 (ed. Zarzycki, J.) 493-548 (VCH, 1991)

49. Kaban, I. et al. Loal atomic arrangements and their topology in $\mathrm{Ni}-\mathrm{Zr}$ and $\mathrm{Cu}-\mathrm{Zr}$ glassy and crystalline alloys. Acta Mater. 61, 2509-2520 (2013).

50. Foppl, L. Stabile anordnungen von elektronen im atom. J. Reine Angew. Math. 141, 251-302 (1912).
51. Kao, S.-W. et al. Predicting the glass-forming-ability of alloys by molecular dynamics simulation: A working example of Ti-Co bulk metallic glasses. Jpn J. Appl. Phys. 48, 061301 (2009).

52. Kawazoe, Y., Yu, J.-Z., Tsai, A.-P. \& Masumoto, T. in Landolt-Bornstein: Numerical Data and Functional Relationships in Science and Technology (ed. Martienssen, W.) 295 (Springer-Verlag, 1997).

53. Chen, H. S., Krause, J. T. \& Sigety, E. A. Thermal expansion and density of glassy Pd-Ni-P and Pt-Ni-P alloys. J. Non Cryst. Solids 13, 321-327 (1973/74).

54. He, Y. \& Schwarz, R. B. in MRS Symposium Proceedings Vol. 455 (eds Angell, C.A., Ngai, K.L., Kieffer, J. \& Egami, T.) 495-500 (Warrendale, PA, USA, 1996).

55. Park, E. S. \& Kim, D. H. Formation of Ca-Mg-Zn bulk glassy alloy by casting into cone-shaped copper mold. J. Mater. Res. 19, 685-688 (2004).

56. Park, E. S., Lee, J. Y. \& Kim, D. H. Effect of Ag addition on the improvement of glass-forming ability and plasticity of $\mathrm{Mg}-\mathrm{Cu}-\mathrm{Gd}$ bulk metallic glass. J. Mater. Res. 20, 2379-2385 (2005).

57. Senkov, O. N. \& Scott, J. M. Glass forming ability and thermal stability of ternary Ca-Mg-Zn bulk metallic glasses. J. Non Cryst. Solids 351, 3087-3094 (2005).

58. Wang, W.-H. \& Bai, H. Y. Role of small atoms in the formation and properties of $\mathrm{Zr}-\mathrm{Ti}$-Cu-Ni-Be bulk amorphous alloys. J. Appl. Phys. 84, 5961-5968 (1998).

59. Waniuk, T. A., Schroers, J. \& Johnson, W. L. Critical cooling rate and thermal stability of $\mathrm{Zr}-\mathrm{Ti}-\mathrm{Cu}-\mathrm{Ni}-\mathrm{Be}$ alloys. Appl. Phys. Lett. 78, 1213-1215 (2001).

60. Zheng, Q., Xua, J. \& Ma, E. High glass-forming ability correlated with fragility of Mg-Cu-Ag-Gd alloys. J. Appl. Phys. 102, 113519 (2007).

\section{Acknowledgements}

We thank O.N. Senkov for critical comments on this manuscript. We also acknowledge the contributions of K. Shamlaye in assisting with supporting data in Supplementary Information and reviewing the manuscript. K.J.L. would like to thank the Australian Research Council for the funding of this and associated projects.

\section{Author contributions}

K.J.L. conceived the efficient packing scheme and applied it to binary, ternary and higher order glass systems. D.B.M. conceived and applied structural self-consistency and applied the suppression concept associated with super-substitutional defects. M.J.F. conceived the super-substitutional defects.

\section{Additional information}

Supplementary Information accompanies this paper at http://www.nature.com/ naturecommunications

Competing financial interests: The authors declare no competing financial interests.

Reprints and permission information is available online at http://npg.nature.com/ reprintsandpermissions/

How to cite this article: Laws, K. J. et al. A predictive structural model for bulk metallic glasses. Nat. Commun. 6:8123 doi: 10.1038/ncomms9123 (2015).

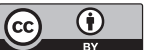

This work is licensed under a Creative Commons Attribution 4.0 International License. The images or other third party material in this article are included in the article's Creative Commons license, unless indicated otherwise in the credit line; if the material is not included under the Creative Commons license, users will need to obtain permission from the license holder to reproduce the material. To view a copy of this license, visit http://creativecommons.org/licenses/by/4.0/ 